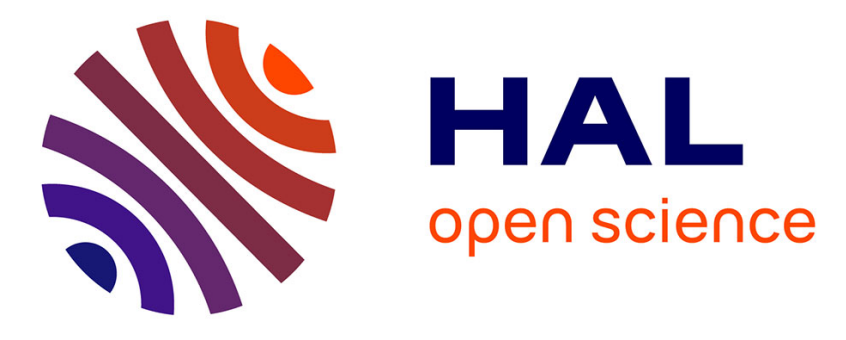

\title{
Supramolecular Assembly of Conjugated Polymers under Vibrational Strong Coupling
}

Kripa Merin Joseph, Soh Kushida, Emanuel Smarsly, Dris Ihiawakrim, Anoop

Thomas, Gian Lorenzo Simone Paravicini Bagliani, Kalaivanan Nagarajan, Robrecht Vergauwe, Eloise Devaux, Ioan-Ovidiu Ersen, et al.

\section{To cite this version:}

Kripa Merin Joseph, Soh Kushida, Emanuel Smarsly, Dris Ihiawakrim, Anoop Thomas, et al.. Supramolecular Assembly of Conjugated Polymers under Vibrational Strong Coupling. Angewandte Chemie International Edition, 2021, 60 (36), pp.19665-19670. 10.1002/anie.202105840 . hal03341524

\section{HAL Id: hal-03341524 \\ https://hal.science/hal-03341524}

Submitted on 10 Sep 2021

HAL is a multi-disciplinary open access archive for the deposit and dissemination of scientific research documents, whether they are published or not. The documents may come from teaching and research institutions in France or abroad, or from public or private research centers.
L'archive ouverte pluridisciplinaire HAL, est destinée au dépôt et à la diffusion de documents scientifiques de niveau recherche, publiés ou non, émanant des établissements d'enseignement et de recherche français ou étrangers, des laboratoires publics ou privés. 


\title{
Supramolecular Assembly of Conjugated Polymers under
}

\section{Vibrational Strong Coupling}

Kripa Joseph ${ }^{\ddagger 1}$ Soh Kushida, ${ }^{\ddagger 1,2}$ Emanuel Smarsly, ${ }^{3}$ Dris Ihiawakrim, ${ }^{4}$ Anoop Thomas, ${ }^{1 \#}$ Gian Lorenzo Paravicini-Bagliani, ${ }^{1}$ Kalaivanan Nagarajan, ${ }^{1}$ Robrecht Vergauwe, ${ }^{1}$ Eloise Devaux, ${ }^{1}$ Ovidiu Ersen, ${ }^{4}$ Uwe H. F. Bunz, ${ }^{3}$ Thomas W. Ebbesen ${ }^{1 *}$

\footnotetext{
${ }^{1}$ University of Strasbourg, CNRS, ISIS, 8 allée Gaspard Monge, 67000 Strasbourg, France ${ }^{2}$ Faculty of Pure and Applied Sciences, University of Tsukuba, 1-1-1 Tennodai, Tsukuba 305-8577, Japan

${ }^{3}$ Organisch-Chemisches Institut, Ruprecht-Karls-Universität Heidelberg, INF 27069120 , Germany

${ }^{4}$ University of Strasbourg, CNRS, IPCMS, 23 rue du Loess, 67034 Strasbourg, France

$\$$ These authors contributed equally to this work.
}

\begin{abstract}
Strong coupling plays a significant role in influencing chemical reactions and tuning material properties by modifying the energy landscapes of the systems. Here we study the effect of vibrational strong coupling (VSC) on supramolecular organization. For this purpose, a rigidrod conjugated polymer known to form gels was strongly coupled together with its solvent in a microfluidic IR Fabry-Perot cavity. Absorption and fluorescence studies indicate a large modification of the self-assembly under such cooperative VSC. Electron microscopy confirms that in this case, the supramolecular morphology is totally different from that observed in the absence of strong coupling. In addition, the self-assembly kinetics are altered and depend on the solvent vibration under VSC. The results are compared to kinetic isotope effects on the self-assembly to help clarify the role of different parameters under strong coupling. These findings indicate that VSC is a valuable new tool for controlling supramolecular assemblies with broad implications for the molecular and material sciences.
\end{abstract}


The impact of light-matter strong coupling on chemical kinetics and chemoselectivity, ${ }^{[1-21]}$ transport, ${ }^{[22-26]}$ work-function, ${ }^{[27]}$ non-linear optics ${ }^{[28,29]}$ and magnetism ${ }^{[30]}$ has opened a new dimension for tuning material properties. In such studies, molecules are placed in the confined resonant electromagnetic field of a cavity or a surface plasmon mode. Under the right conditions, hybrid light-matter states are formed, causing changes in properties. This occurs even in the dark due to the involvement of the zero-point energy fluctuations of the material and optical transitions. In the last several years, it has been shown that coupling vibrational modes in this way has a pronounced effect on chemistry and molecular properties ${ }^{[3,5-17,20]}$. In this vibrational strong coupling regime (VSC), vibro-polaritonic states (VP+, VP-) are formed, separated by the so-called Rabi splitting energy ( $\left.\hbar \Omega_{R}\right)$ (Figure $\left.1 \mathrm{a}\right)$. In typical experiments, a large number $\mathrm{N}$ of molecules are coupled by VSC to a single optical mode which leads to the formation of N-1 dark states (DS) which are, together with VP+ and VP-, delocalized over many molecules. Note that the DS are not necessarily centered between VP+ and VP-. ${ }^{[31]}$ If a solute and a solvent have vibrational modes at the same frequency, it is possible to couple the solute via the solvent to achieve VSC. This process, cooperative coupling, ${ }^{[6,7,21,30]}$ is used in this study of supramolecular assembly.

Supramolecular systems are dominated by non-covalent intermolecular interactions such as hydrogen bonding, dispersive forces, electrostatic, hydrophobic and $\pi-\pi$ interactions. ${ }^{[32-}$ 35] Therefore solvent molecules play a key role in determining stability, thermodynamics and kinetics of self-assembly of molecules through different stages of aggregation. ${ }^{[36]}$ Dynamics and morphology of supramolecular assembly can also be modulated and regulated via external stimuli such as heat, ${ }^{[37]}$ light, ${ }^{[38-40]}$ sound, ${ }^{[41]}$ mechanical force, ${ }^{[42]}$ chemical, electrochemical and magnetic effects ${ }^{[43,44]}$ and localized surface plasmons. ${ }^{[45]}$ Self-assembly is critical for applications such as sensing, tissue engineering, and drug delivery. 
Recently Hirai et al reported that VSC of the solvent could drive selective crystallization of metal-organic frameworks (MOFs), suggesting that VSC can alter molecular organization. ${ }^{[20]}$ Here we demonstrate that VSC modifies supramolecular assembly and its dynamics. We study the gelation of rigid-rod conjugated polymers under strong coupling. For years, these polymers have been of great interest for sensor and OLED applications due to their

a)

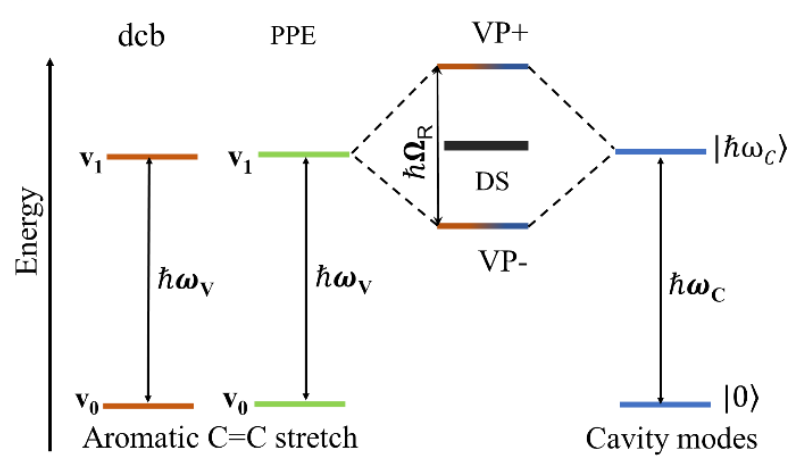

c)

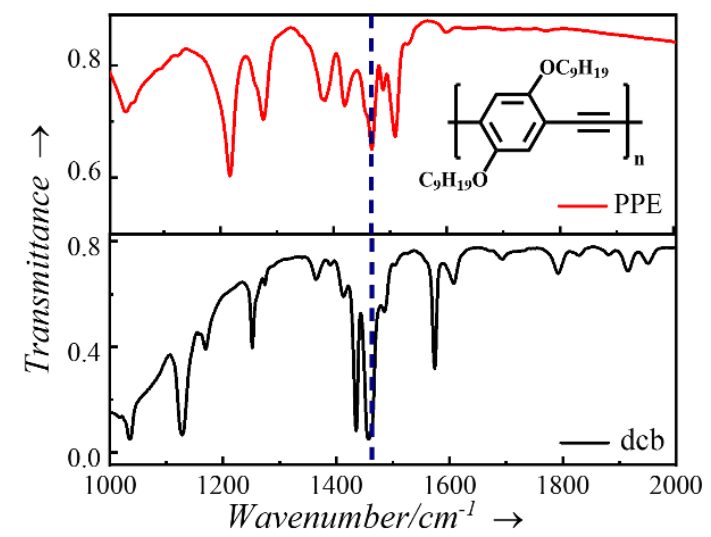

b)

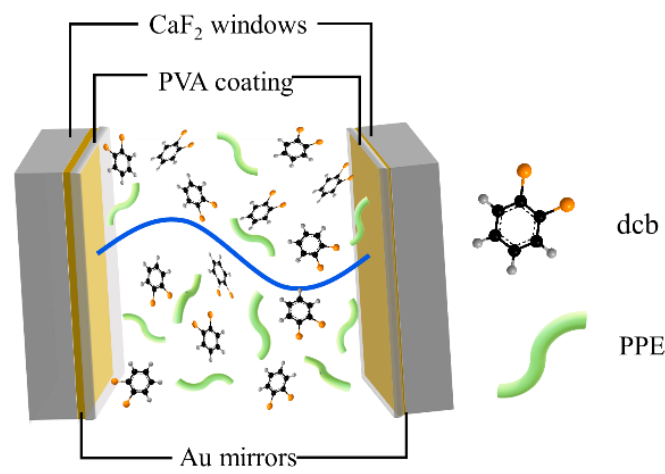

d)

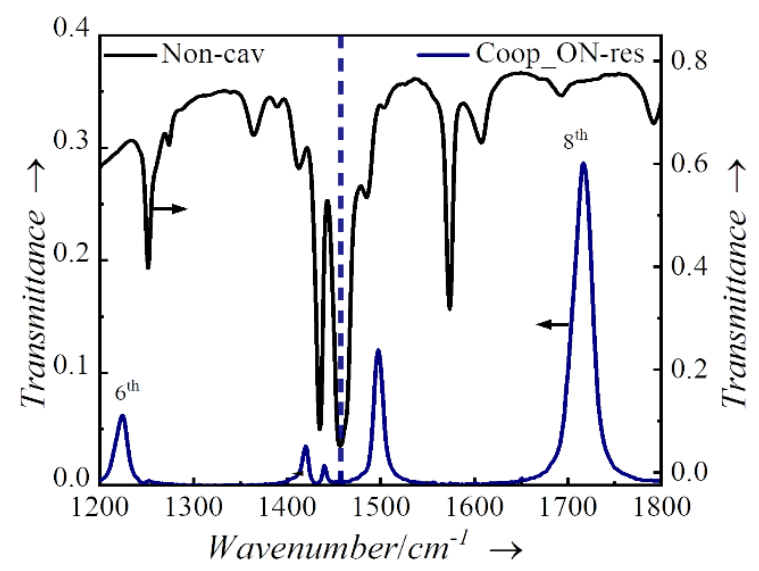

Figure 1. a) Schematic representation of cooperative strong coupling between molecular vibration and optical mode of Fabry-Perot cavity leading to the formation of vibro-polaritonic states. b) Illustration of a microfluidic Fabry-Perot cavity containing a molecular solution. c) FT-IR transmission spectra of PPE (red curve) and dcb (black curve), blue dashed line shows the overlap of aromatic $\mathrm{C}=\mathrm{C}$ stretch in PPE and dcb at $1460 \mathrm{~cm}^{-1}$ and the inset shows the chemical structure of dinonanoyloxy-substituted poly(para-phenyleneethynylene) (PPE). d) FT-IR transmission spectra showing the vibro-polaritonic states formed when the aromatic $\mathrm{C}=\mathrm{C}$ stretching mode at $1460 \mathrm{~cm}^{-1}$ of the PPE/dcb solution is strongly coupled to the cavity. 
opto-electronic properties such as luminescence and efficient charge transfer because of the extended conjugation between the triple bonds and the adjacent phenyl groups. ${ }^{[46-51]}$

For the purpose of our study, we selected dinonanyloxy-substituted poly(paraphenyleneethynylene) (PPE, inset of Figure 1c). The gelation behavior of PPEs with alkyl- or alkoxy-side-chains has been well investigated. ${ }^{[52,53]}$ Concentrated solutions of PPEs form onedimensional nanowires growing into a fibrous network via thermal saturation. ${ }^{[54]}$ In its gelform, PPEs exhibit lamellar packing which is responsible for the appearance of a well-resolved planarization band in the absorption spectra. ${ }^{[55-58]}$ In general, both the absorption and the fluorescence spectra of PPEs are sensitive to molecular packing.

To study the effects of VSC on the supramolecular organization of PPE, microfluidic tunable optical Fabry-Perot (FP) cavities were used. The FP cavity (Figure 1b) consists of two parallel mirrors which were fabricated by sputtering $10 \mathrm{~nm}$ of $\mathrm{Au}$ on $\mathrm{CaF}_{2}$ substrates and protecting them with $100 \mathrm{~nm}$ thick layer of spin-coated polyvinyl alcohol (PVA). The two mirrors were separated by a $10 \mu \mathrm{m}$ thick Mylar spacer and assembled into a microfluidic cell. The spacing between the two mirrors is finely tuned with four screws holding the microfluidic cell together (see url: https://seafile.unistra.fr/d/7bb78e5a4607424f94b5/) to couple the desired vibrational mode of the solvent o-dichlorobenzene (dcb) in which PPE is dissolved. 
a)

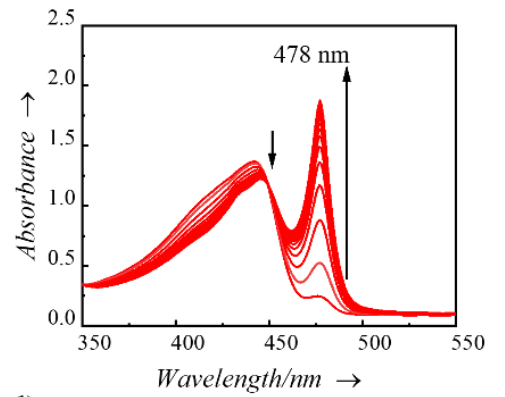

d)

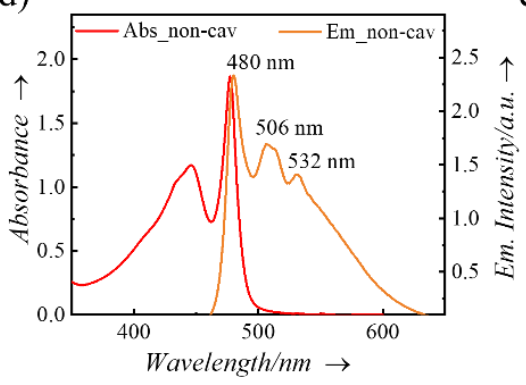

b)

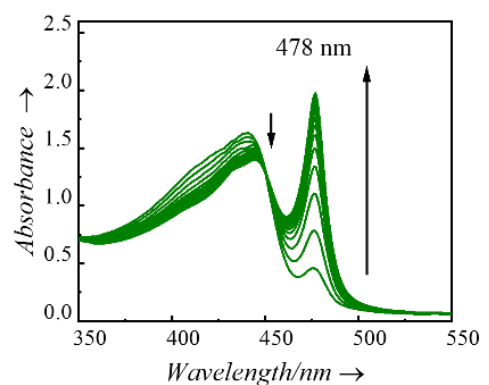

e)

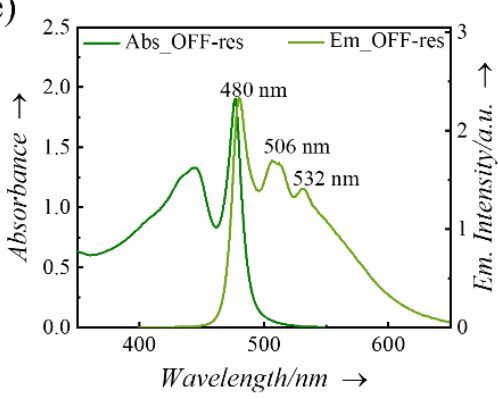

c)

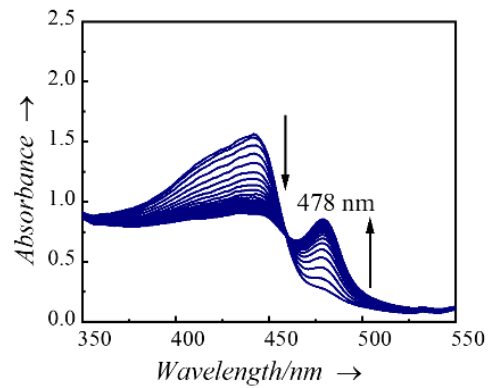

f)

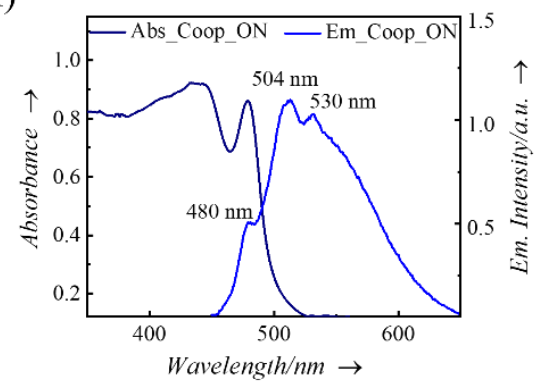

Figure 2. Absorption spectra showing the evolution of self-assembly in a) non-cavity, b) OFFresonance and c) ON-resonance cavities. Absorption and emission spectra of the selfassembled structures recorded in d) non-cavity, e) OFF-resonance and f) ON-resonance cavities.

Figure 1c shows the vibrational spectra of PPE and dcb and due to the low concentration of PPE in dcb, the FTIR transmission spectrum of the solution is dominated by that of solvent (Figure 1d). To achieve strong coupling of PPE, cooperative VSC at $1460 \mathrm{~cm}^{-1}$ is used, where the aromatic $\mathrm{C}=\mathrm{C}$ stretching mode of both PPE and dcb overlap. As seen in Figure $1 \mathrm{~d}$, strong coupling was achieved with the $7^{\text {th }}$ optical mode of the FP cavity. The Rabi splitting $\left(\hbar \boldsymbol{\Omega}_{\mathrm{R}}, 62\right.$ $\left.\mathrm{cm}^{-1}\right)$ is larger than the FWHM of the optical $\left(24 \mathrm{~cm}^{-1}\right)$ and vibrational modes (PPE and dcb: 19 and $29 \mathrm{~cm}^{-1}$ ). Note that the solvent vibrational mode at $1435 \mathrm{~cm}^{-1}$ in the vicinity of the coupled band splits the VP- peak, nevertheless as we will see further down, it does not induce any change in the supramolecular assembly. For control experiments, we prepared cavities without $\mathrm{Au}$ mirrors ("non-cavity") by only spin-coating PVA on $\mathrm{CaF}_{2}$ windows. We also 
repeated the same experiment in the FP cavity that is detuned from the vibrational mode ("OFFresonance" cavities), as an additional reference.

Figures 2 a-c show the progression of supramolecular self-assembly followed with a Shimadzu spectrophotometer in the visible spectrum at $24^{\circ} \mathrm{C}$ in non-, OFF- and $\mathrm{ON}$ - resonance cavities. In non- and OFF-resonance cavities, the results are identical with the appearance of a sharp maximum at $478 \mathrm{~nm}$ corresponding to band of the planarization (planar assembly of the PPE), as well as a slight decrease in the band at $440 \mathrm{~nm}$ in agreement with the literature. ${ }^{[54-}$ ${ }^{58]}$ Spectral evolution under ON-resonance is completely different with a red-shifted isobestic point suggesting a new type of assembly. The band at $478 \mathrm{~nm}$ is less pronounced and the 440 $\mathrm{nm}$ band is red-shifted and broader. The self-assembly rate constant increases by ca. $20 \%$ under cooperative VSC (see Table 1).

Figures $2 \mathrm{~d}$-f show the final absorption and fluorescence spectra of the assemblies. The latter are again very different for the supramolecular assembly under cooperative VSC. Finally, VSC of other vibrational bands of the solvent such as the ones at $1127 \mathrm{~cm}^{-1}$ (C-H deformation mode) and $1435 \mathrm{~cm}^{-1}$ (asymmetric aromatic $\mathrm{C}=\mathrm{C}$ stretching mode) modify the kinetics as summarized in Table 1. While the absorption spectra of the final assembly are very similar to the non-cavity case, there is a small $4 \mathrm{~nm}$ shift in the isobestic points (Figures S3 and S4) indicating some change in the organization at the molecular scale. It should be recalled that in these cases, only the solvent is coupled.

To verify whether the supramolecular organization is modified under cooperative VSC, the resulting assemblies were characterized by scanning and transmission electron microscopies (SEM and TEM). The different cavities were opened after the evaporation of solvent and $\mathrm{CaF}_{2}$ substrates were directly studied first by SEM. The deformation of $\mathrm{CaF}_{2}$ windows under tuning restricts the $\mathrm{ON}$-resonance region to the tuned central area of the cavity. When analyzing this area, the SEM images of material in non-cavity and ON-resonance cavity 
show a significant difference in the structure of the supramolecular organization (Figures 3 a and d). A fibrous network is seen for both non- and OFF-resonance cavities which is typical of PPE self-assembled structures. In contrast, for the ON-resonance condition, the PPE formed large flakes as seen in Figure 3d.

Table 1: Morphology and rate constants of the PPE supramolecular assembly.

\begin{tabular}{|c|c|c|c|c|}
\hline Experiment & $\begin{array}{c}\text { Vibrational mode } \\
\left(\mathrm{cm}^{-1}\right)\end{array}$ & $\begin{array}{l}\text { Rabi splitting } \\
\left(\hbar \boldsymbol{\Omega}_{\mathrm{R}}, \mathrm{cm}^{-1}\right)\end{array}$ & Morphology & $\begin{array}{l}\text { Rate constant } \\
\qquad\left(10^{-3} \mathrm{sec}^{-1}\right)\end{array}$ \\
\hline
\end{tabular}

Non-cavity

OFF-resonance

Coop. ON-resonance ${ }^{\S}$

ON-resonance ${ }^{\dagger}$

ON-resonance ${ }^{\dagger}$
1460

1435

1127
62

40

46

\section{PPE/D4-dcb}

Non-cavity

ON-resonance ${ }^{\dagger}$

1345
Flakes

64
Fibers

\section{Fibers}

Fibers

$6.2 \pm 0.19$

$6.3 \pm 0.25$

Flakes

$7.4 \pm 0.07$

Fibers

$8.1 \pm 0.21$

$1.8 \pm 0.02$

$\S=$ ON-resonance cavity experiment under cooperative VSC of solvent and solute; $\uparrow=\mathrm{ON}-$ resonance cavity experiments with VSC of only solvent. $*=$ no simple kinetic rate could be extracted.

To further understand the packing structures on a smaller scale, PPE self-assembled material was transferred to a TEM grid and imaged. Figures $3 \mathrm{~b}$ and $\mathrm{c}$ reveal the ordered lamellar 
packing of the PPE fibers in agreement with the literature. ${ }^{[55,58]}$ For ON-resonance cavity on the other hand, the flakes are completely amorphous as seen in Figure $3 \mathrm{e}$ and $\mathrm{f}$.
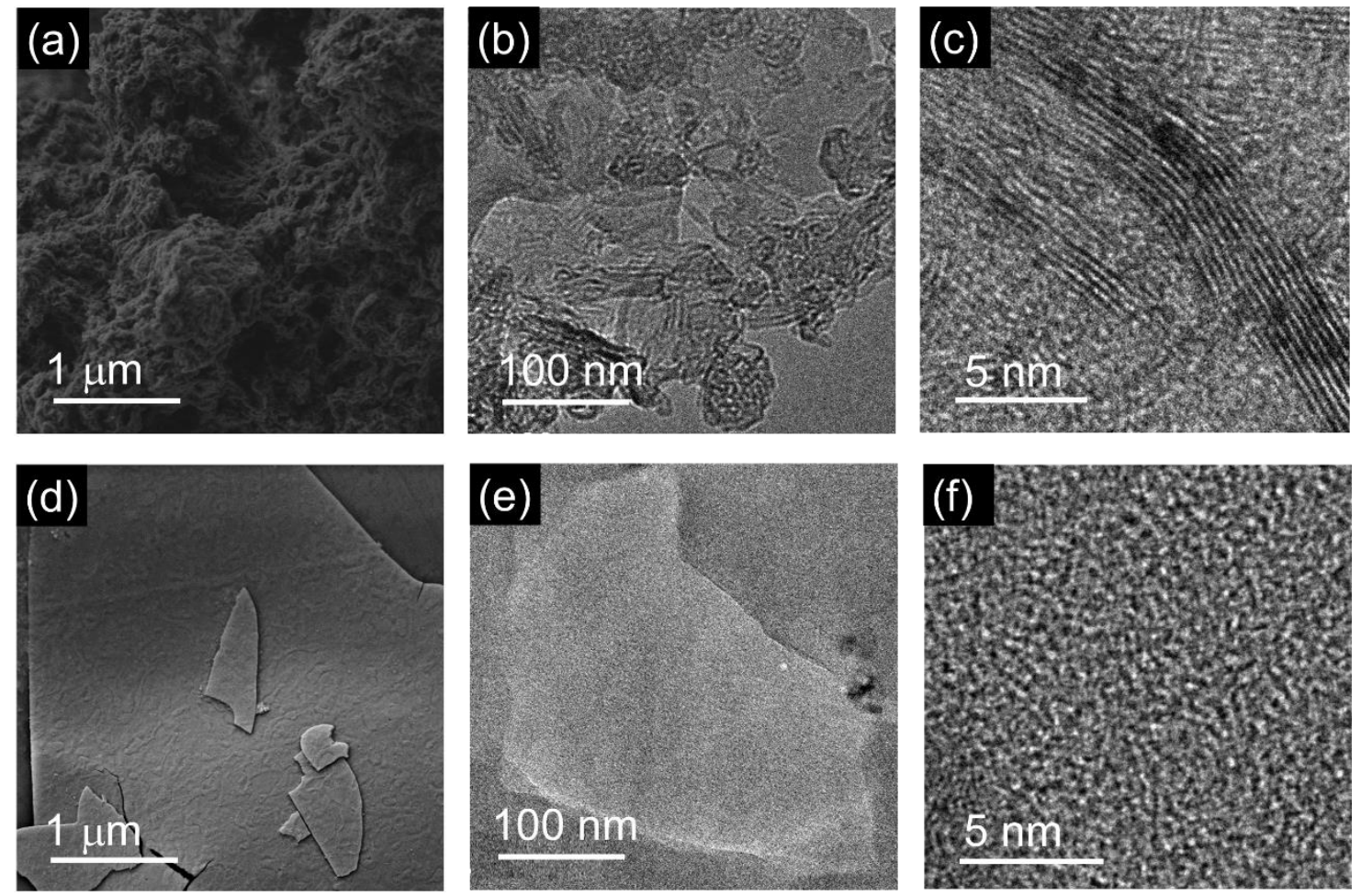

Figure 3. SEM and TEM images of PPE rigid polymer forming fibrous network in non-cavity (a-c) and flakes under cooperative VSC (d-f). a) and d) are SEM images and b), c), e) and f) are TEM images.

In Table 1, it is clear that while cooperative VSC perturbs both the kinetics and the morphology of the PPE supramolecular assembly, coupling of the solvent alone just leads to kinetic changes. In order to gain further insight into the factors influencing these results, the PPE assembly was studied in a deuterated solvent, 1,2-dichlorobenzene- $\mathrm{D}_{4}$. While cooperative coupling is not possible in this case because none of the vibrations of this deuterated solvent match that of PPE, the spectral changes in a non-cavity (deuterated) are very similar to the ONresonance under cooperative VSC (Figure 2c, non-deuterated) with the appearance of flakes as shown in Figure 4. Under VSC of the deuterated solvent, nothing changed in morphology and 
spectra with respect to the non-cavity of the same solvent as summarized in Table 1 and shown in Figure S5. These differences between the isotope effect and VSC shows that the effects of VSC is not just due to changes in the vibrational frequencies of the coupled mode. Furthermore, there is no evidence of kinetically trapped states, as can be seen in Table 1, unlike other studies. $[55,60]$
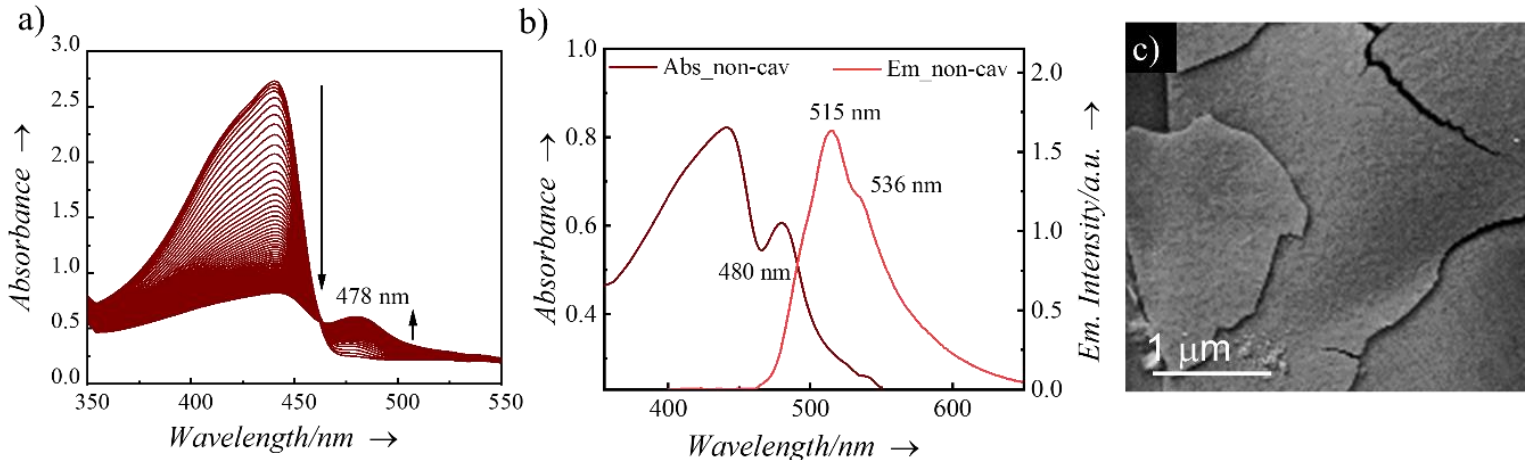

Figure 4. a) Absorption spectra showing the evolution of self-assembly of PPE in D4-dcb in non-cavity.

b) Absorption and emission spectra of the self-assembled structure of a). c) SEM image of flakes of PPE formed in D4-dcb in non-cavity.

As known from quantum electrodynamics, universal vacuum electromagnetic field fluctuations occur everywhere and play an important role in van der Waals dispersive forces. ${ }^{[61]}$ Therefore it is perhaps not surprising that the supramolecular interactions are modified under strong coupling with the vacuum field. Changes in solvent polarizability, polarity and dynamics under strong coupling may be at play. ${ }^{[18,19]}$ After all, solvent polarity plays a role in determining the degree of aggregation as it affects the solubility of molecules. ${ }^{[59,62]}$ In addition, solvent coupling has been found to have a pronounced impact on enzymatic activity ${ }^{[3-6]}$ and to modify the polymorphism of metal-organic frameworks. ${ }^{[20]}$ Together with the present results, it points to the fact that solvent properties and solvation can be altered by VSC.

The modification of supramolecular organization under VSC is a powerful example of the potential of strong coupling to control molecular processes. Once the complex effect of 
VSC on solvents and intermolecular interactions are better understood, its full potential for supramolecular organization will be unlocked and become a new tool box.

\section{Present address:}

\# Department of Inorganic and Physical Chemistry, Indian Institute of Science, Bengaluru, 560012 - Bengaluru, India

\section{Acknowledgments:}

We acknowledge support of the International Center for Frontier Research in Chemistry (icFRC, Strasbourg), the ANR Equipex Union (ANR-10-EQPX-52-01), CSC (ANR-10LABX- 0026 CSC) within the Investissement d'Avenir program ANR-10-IDEX-0002-02 and the H2020-MSCAITN project no. 811284 UHMob. TWE acknowledges the support of the ERC (project no 788482 MOLUSC). S.K. is grateful to JSPS Kakenhi (grant number JP20J00845).

The authors declare no competing financial interest. 


\section{References}

(1) T. W. Ebbesen, Acc. Chem. Res. 2016, 49, 2403-2412.

(2) J. A. Hutchison, T. Schwartz, C. Genet, E. Devaux, T. W. Ebbesen, Angew. Chem. Int. Ed. 2012, 51, 1592-1596.

(3) A. Thomas, J. George, A. Shalabney, M. Dryzhakov, S. J. Varma, J. Moran, T. Chervy, X. Zhong, E. Devaux, C. Genet, J.A. Hutchison, T.W. Ebbesen, Angew. Chem. Int. Ed. 2016, 55, 11462-11466.

(4) J. Feist, J. Galego, F. J. Garcia-Vidal, ACS Photonics 2018, 5, 205-216.

(5) R. M. A.Vergauwe, A. Thomas, K. Nagarajan, A. Shalabney, J. George, T. Chervy, M. Seidel, E. Devaux, V. Torbeev, T. W. Ebbesen, Angew. Chem. Int. Ed. 2019, 58, 1532415328.

(6) J. Lather, J. George, J. Phys. Chem. Lett. 2021, 12, 379-384.

(7) J. Lather, P. Bhatt, A. Thomas, T.W. Ebbesen, J. George, Angew. Chem. Int. Ed. 2019, 58, 10635-10638.

(8) A. Sau, K. Nagarajan, B. Patrahau, L. Lethuillier-Karl, R. Vergauwe, A. Thomas, J. Moran, C. Genet, T.W. Ebbesen, Angew. Chem. Int. Ed. 2021, 133, 5776-5781.

(9) Y. Pang, A. Thomas, K. Nagarajan, R. M. A. Vergauwe, K. Joseph, B. Patrahau, K. Wang, C. Genet, T. W. Ebbesen, Angew. Chem. Int. Ed. 2020, 59, 10436-10440.

(10) K. Hirai, R. Takeda, J.A. Hutchison, H. Uji-i, Angew. Chem. Int. Ed. 2020, 59, 5332-5335.

(11) J. A. Campos-Gonzalez-Angulo, R.F. Ribeiro, J. Yuen-Zhou, Nat. Commun. 2019, 10, 4685.

(12)F.J. Hernandez, F. Herrera J. Chem. Phys. 2019, 151, 144116.

(13) A. Thomas, L. Lethuillier-Karl, K. Nagarajan, R. M. A. Vergauwe, J. George, T. Chervy, A. Shalabney, E. Devaux, C. Genet, J. Moran, T. W. Ebbesen, Science 2019, 363, 615-619.

(14) I. Vurgaftman, B.S. Simpkins, A. D. Dunkelburger, J.C. Owrutsky, J. Phys. Chem. Lett 2020, 11, 3557-3562.

(15) N.T. Phuc, P.Q. Trung, A. Ishizaki, Sci. Rep. 2020, 10, 7318.

(16) T.E. Li, J.E. Subotnik, A. Nitzan, Proc. Natl. Acad. Sci. USA 2020, 117, 18324-18331.

(17) X. Li, A. Mandal, P. Huo, Nat. Commun. 2021, 12, 1315.

(18) J. Flick, C. Schäfer, M. Ruggenthaler, H. Appel, A. Rubio, ACS Photonics 2018, 5, 9921005.

(19) T. S. Haugland, C. Schäfer, E. Ronca, A. Rubio, H. Koch, J. Chem. Phys 2021, 154, 094113.

(20) K. Hirai, H. Ishikawa, J. A. Hutchison, H. Uji-i, ChemRxiv 2020, ver. 2. https://doi.org/10.26434/chemrxiv.13191617.v2.

(21) S. Schütz, J. Schachenmayer, D. Hagenmüller, G.K. Brennen, T. Volz, V. Sandoghdar, T.W. Ebbesen, C. Genes, G. Pupillo, Phys. Rev. Lett. 2020, 124, 113602.

(22) E. Orgiu, J. George, J. A. Hutchison, E. Devaux, J. F. Dayen, D. Doudin, F. Stellacci, C. Genet, J. Schachenmayer, C. Genes, G. Pupillo, P. Samori, T. W. Ebbesen, Nat. Mater. 2015, 14, 1123-1129.

(23) K. Nagarajan, J. George, A. Thomas, E. Devaux, T. Chervy, S. Azzini, K. Joseph, A. Jouaiti, M. W. Hosseini, A. Kumar, C. Genet, N. Bartolo, C. Ciuti, T. W. Ebbesen, ACS Nano 2020, 14, 10219-10225.

(24) J. Schachenmayer, S. Schütz, C. Genes, G. Pupillo, Phys. Rev. Lett. 2017, 119, 223601.

(25) G. G. Rozenman, K. Akulov, A. Golombek, T. Schwartz, ACS Photonics 2018, 5, 105-110.

(26) N. Krainova, A.J. Grede, D. Tsokkou, N. Banerji, N.C. Giebink, Phys. Rev. Lett. 2020, 124, 177401.

(27) J. A. Hutchison, A. Liscio, T. Schwartz, A. Canaguier-Durand, C. Genet, V. Palermo, P. Samorì, T. W. Ebbesen, Adv. Mater. 2013, 25, 2481-2485. 
(28) T. Chervy, J. Xu, Y. Duan, C. Wang, L. Mager, M. Frerejean, et al, Nano Lett. 2016, 16, $7352-7356$.

(29) K. Wang, M. Seidel, K. Nagarajan, T. Chervy, C. Genet, T. W. Ebbesen, Nat. Commun. 2021, 12, 1486.

(30) A. Thomas, E. Devaux, K. Nagarajan, G. Rogez, M. Seidel, F. Richard, C. Genet, M. Drillon, T. W. Ebbesen, Nano Letters in press 2021.

(31) G. D. Scholes, C. A. Delpo, B. Kudisch, J. Phys. Chem. Lett. 2020, 11, 6389-6395.

(32) J.L. Atwood, J.E.D. Davies, D.D. MacNicol, F. Vögtle, J.-M. Lehn, (eds) Comprehensive Supramolecular Chemistry, Pergamon, Oxford, 1996.

(33) J.-M. Lehn, Eur. Rev. 2009, 17, 263-280.

(34) T. F. A. De Greef, M. M. J. Smulders, M. Wolffs, A. P. H. J. Schenning, R. P. Sijbesma, E. W. Meijer, Chem. Rev. 2009, 109, 5687-5754.

(35)F. Würthner, Acc. Chem. Res. 2016, 49, 868-876.

(36) P. Jonkheijm, P. van der Schoot, A. P. Schenning, E. W. Meijer, Science 2006, 313, 80-83.

(37) A Ajayaghosh, S. J. George, J. Am. Chem. Soc. 2001, 123, 5148-5149.

(38) D. Zhao, T. van Leeuwan, J. Cheng, B. Feringa, Nat. Chem. 2017, 3, 250-256.

(39) J. Chen, F. King-Chi Leung, M.C.A. Stuart, T. Kajitani, T. Fukushima, E. van der Giessen, B. Feringa, Nat. Chem. 2018, 10, 132-138.

(40) B. Adhikari, Y. Yamada, M. Yamauchi, K. Wakita, X. Lin, K. Aratsu, T. Ohba, T. Karatsu, M. J. Hollamby, N. Shimizu, H. Takagi, R. Haruki, S. Adachi, S. Yagai, Nat. Commun. 2017, 8, 15254.

(41) G. Cravotto, P. Cintas, Chem. Soc. Rev. 2009, 38, 2684-2697.

(42)C.L. Guo, M. Ouyang, J. Y. Yu, J. Maslov, A. Price, C. Shen, Proc. Natl. Acad. Sci. USA 2012, 109, 5576-5582.

(43) K. Cui, K. S. Mali, O. Ivasenko, D. Wu, X. Feng, M. Walter, K. Müllen, S. De Feyter, S. F. L. Mertens, Angew. Chem. Int. Ed. 2014, 53, 12951-12954.

(44) S. Bitter, M. Schlötter, M. Schilling, M. Krumova, S. Polarz, R. F. Winter, Chem. Sci. 2021, 12, 270-281.

(45) M. Quint, S. Sarang, D. A. Quint, A. Keshavarz, B. J. Stokes, A. B. Subramaniam, K. C. Gopinathan, L. S. Hirst, S. Ghosh, Sci. Rep. 2017, 7, 17788.

(46) A. Montali, P. Smith, C. Weder, Synth. Met. 1998, 97, 2,123-126.

(47) S. Kushida, S. Kebrich, E. Smarsly, K. P. Strunk, C. Melzer, U. H. F. Bunz, ACS Appl. Mater. Interfaces 2020, 12, 38483-38489.

(48) T. B. Singh, F. Meghdadi, S. Günes, N. Marjanovic, G. Horowitz, P. Lang, S. Bauer, N. S. Sariciftci, Adv. Mater. 2005, 17, 2315-2320.

(49) N. G. Pschirer, K. Byrd, U. H. F. Bunz, Macromolecules 2001, 34, 8590-8592.

(50) R. Schroeder, J. N. Wilson, U. H. F. Bunz, B. Ullrich, J. Phys. Chem. B 2003, 107, 1160411607.

(51) S. Kushida, E. Smarsly, K. Yoshinaga, I. Wacker, Y. Yamamoto, R. R. Schröder, U. H. F. Bunz, Adv. Mater. 2021, 33, 2006061.

(52) W. Y. Huang, S. Matsuoka, T. K. Kwei, Y. Okamoto, Macromolecules 2001, 34, 71667171.

(53)D. Perahia, R. Traiphol, U. H. F. Bunz, J. Chem. Phys. 2002, 117, 1827-1832.

(54) S. Kushida, E. Smarsly, L. Veith, I. Wacker, R. R. Schroder, U. H. F. Bunz, Macromolecules 2017, 50, 7880-7886.

(55) U. H. F. Bunz, J. M. Imhof, R. K. Bly, C. G. Bangcuyo, L. Rozanski, D. A. V. Bout, Macromolecules 2005, 38, 5892-5896.

(56) U. H. F. Bunz, V. Enkelmann, L. Kloppenburg, D. Jones, K. D. Shimizu, J. B. Claridge, Chem. Mater. 1999, 11, 1416-1424.

(57) M. I. Sluch, A. Godt, U. H. F. Bunz, M. A. Berg, J. Am. Chem. Soc. 2001, 123, 6447-6448. 
(58) M. Levitus, K. Schmieder, H. Ricks, K. D. Shimizu, U. H. F. Bunz, M. A. Garcia-Garibay, J. Am. Chem. Soc. 2001, 123, 4259-4265.

(59) Y-Q. Huang, Q-L. Fan, X-M. Lu, C. Fang, S-J. Liu, L-H. Yu-Wen, L-H. Wang, W. Huang, J. Polym. Sci. Pol. Chem. 2006, 44, 5778-5794.

(60) T. Fukui, S. Kawai, S. Fujinuma, Y. Matsushita, T. Yasuda, T. Sakurai, S. Seki, M. Takeuchi, K. Sugiyasu, Nat. Chem. 2017, 9, 493-499.

(61) S. Haroche, D. Kleppner, Phys. Today 1989, 42, 1, 24-30.

(62) E. Smarsly, D. Dominik, R. Tone, L. Veith, E. R. Curticean, I. Wacker, R. R. Schröder, H. M. Sauer, E. Dörsam, U. H. F. Bunz, ACS Appl. Mater. Interfaces 2018, 11, 3317-3322.

TOC

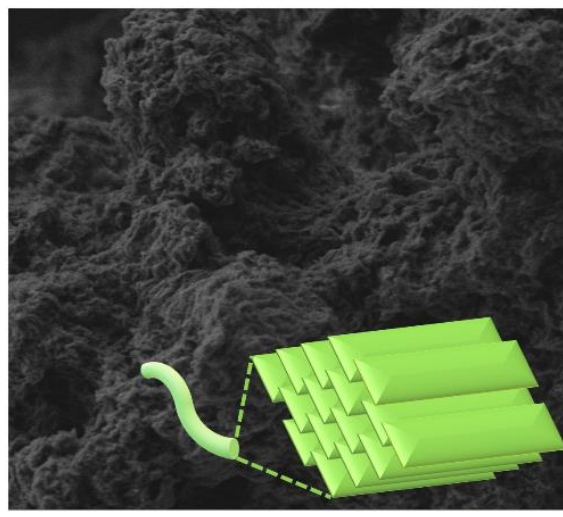

Cooperative VSC 